\title{
Assessing the Effects of Marine Protected Areas on Biological Invasions: A Global Review
}

\author{
Sylvaine Giakoumi ${ }^{1,2 *}$ and Alexis Pey ${ }^{1}$ \\ ${ }^{1}$ Centre National de la Recherche Scientifique, ECOMERS, Université Côte d'Azur, Nice, France, ${ }^{2}$ ARC Centre of Excellence \\ for Environmental Decisions, School of Biological Sciences, The University of Queensland, Brisbane, QLD, Australia
}

OPEN ACCESS

Edited by:

Trevor John Willis,

University of Portsmouth, UK

Reviewed by:

Alex Caveen

Seafish Industry Authority, UK Keryn Gedan,

George Washington University, USA

*Correspondence:

Sylvaine Giakoumi sylvaine.giakoumi1@gmail.com

Specialty section:

This article was submitted to Marine Conservation and Sustainability,

a section of the journal Frontiers in Marine Science

Received: 29 November 2016 Accepted: 13 February 2017 Published: 28 February 2017

Citation:

Giakoumi S and Pey A (2017) Assessing the Effects of Marine Protected Areas on Biological

Invasions: A Global Review.

Front. Mar. Sci. 4:49.

doi: 10.3389/fmars.2017.00049
Marine protected areas (MPAs) have proven to be an effective tool to conserve marine biodiversity and restore ecosystem functioning. Yet, the role of MPAs in providing resilience to global threats, such as biological invasions, is poorly understood. Assessing the effects of MPAs on invasive species is crucial for effective MPA planning and management. We conducted a peer-reviewed literature survey to synthesize all available information on the performance of alien/invasive species in MPAs at a global scale. We also assessed the effects of protection on such species following a meta-analytical approach. We found only 17 studies that were suitable for the qualitative and quantitative synthesis. We included studies that provided data on alien species from both inside and outside MPAs. The largest proportion of the available literature provided data on alien molluscs (40\%), followed by algae (28\%). Information on the effects of protection on alien/invasive species is available for only $11 \%$ of the marine biogeographic provinces; principally, for the Mediterranean and Caribbean Seas. Only four studies provided adequate quantitative data to estimate the effect of protection on the density and biomass of 12 alien species. We found that protection had a significant negative effect on half the species, whereas 33\% of the species were positively affected. Our review demonstrates the scarcity of data on this crucial topic. More evidence on various species and taxonomic groups across marine regions is necessary to draw robust conclusions.

Keywords: alien species, biogeographic regions, biological invasions, effect size, global review, marine protected areas

\section{INTRODUCTION}

Biological invasions are a major factor of global change that cause negative impacts on native biodiversity and ecosystem functioning (Pyšek and Richardson, 2010; Simberloff et al., 2013; Katsanevakis et al., 2014a; Vergés et al., 2016). In the marine environment, alien species (i.e., organisms introduced outside their natural range) can become invasive and cause numerous ecological changes such as the loss of native genotypes, degradation of habitats, changes in trophic interactions, and displacement of native species (Molnar et al., 2008; Albins, 2013; Giakoumi, 2014; Vergés et al., 2014, 2016). Furthermore, marine invasive species may have negative socio-economic impacts on fisheries and recreational activities, e.g., decline of commercial fish stocks (Bax et al., 2003; Katsanevakis et al., 2014b). Although marine biological invasions have been recognized as one of the major threats of marine ecosystems (Halpern et al., 2008; Molnar et al., 2008), the uptake of management actions to mitigate their impacts falls short (Thresher and Kuris, 2004; Giakoumi et al., 2016). 
Marine protected areas (MPAs) form the cornerstone of marine conservation. They have emerged as a prominent management tool for the conservation and recovery of marine ecosystems and their ecosystem services (Lubchenco and Grorud-Colvert, 2015). The level of protection in MPAs varies from fully protected, where all extractive activities are prohibited, to partially protected, where some extractive activities occur with varying restrictions (Lubchenco et al., 2016). The ecological effects of fully protected areas (also called "no-take zones" or "marine reserves") include increases in sizes of organisms, density and biomass of commercially exploited species and whole assemblages, reproductive potential, species richness, live cover of benthic organisms, and restoration of trophic interactions (e.g., Guidetti and Sala, 2007; Selig and Bruno, 2010; Edgar et al., 2014). Despite the availability of a large amount of information on MPAs, the effects of protection on marine alien species remain largely unknown (Burfeind et al., 2013; Ardura et al., 2016; Giakoumi et al., 2016).

Different mechanisms could explain how MPAs can control the presence and reduce the impacts of alien species within their borders. First, vectors of alien species are expected to be fewer in MPAs, because many human uses, such as aquaculture and marine traffic, are forbidden or restricted (Ardura et al., 2016). Secondly, based on the "biotic resistance hypothesis" (i.e., ecosystems with high species richness are more resistant to invaders than those with low biodiversity; Levine and D'Antonio, 1999), the high native species richness within MPAs could prevent the penetration and settlement of alien species. Thirdly, the restoration of top-down regulation processes (e.g., restoration of top predators' populations) in MPAs could help control the population of some alien species inside MPAs (e.g., Mumby et al., 2011 but see also Hackerott et al., 2013). On the other hand, several mechanisms could support the opposite argument, that MPAs favor the spreading of alien species. For example, according to the "biotic acceptance hypothesis" ecosystems can accommodate the establishment of aliens and their coexistence with native species, and based on a rich-get-richer pattern, areas with high native species richness could support high numbers of alien species (Stohlgren et al., 2006; Fridley et al., 2007). Moreover, harvested alien species could be enhanced in MPAs, mainly because they would benefit from harvesting bans and restrictions applying within the MPA (Burfeind et al., 2013). Finally, MPAs may have no effect on alien species as most of them have dispersal mechanisms that expand beyond the MPA boundaries (Burfeind et al., 2013).

Assessing the effects of MPAs on invasive species is crucial for the effective management of existing MPAs as well as for the optimal site selection for future MPAs (Giakoumi et al., 2016). If MPAs prove to have no effect or favor the settlement and expansion of invasive species, then the location of new MPAs in impacted areas should either be avoided (Boudouresque and Verlaque, 2005), or complemented with other management measures for the mitigation of invasive species' impacts (Thresher and Kuris, 2004). Here, building on previous efforts (Burfeind et al., 2013), we aim to synthesize all available information on this important topic at a global scale and assess the effects of MPAs on alien/invasive species following a meta-analytical approach.

\section{MATERIALS AND METHODS}

\section{Literature Review}

We conducted a comprehensive survey of the peer-reviewed literature to compile a database of studies that investigated the effects of MPAs on alien species. We used the research engine Web of Science (https://www.webofknowledge.com). Eligibility criteria included any paper or review published between 1950 and the cut-off date 10 June 2016 with the terms: "marine protected area*," "marine reserve*," "no-take area*," "no-take zone*," "marine park" in the title, keywords and/or abstract. Each of these searches where refined using the terms: "exotic," "alien," "invasive," "non-indigenous," "NIS," "non-native," "introduced species," "foreign species." The results summed up to 284 peerreviewed papers.

Our review started with a screening of the 284 paper abstracts. Articles were excluded if they: (1) were unrelated to a protected area in the marine environment, (2) were unrelated to alien species, (3) took into account only terrestrial or freshwater species and not marine, (4) were theoretical studies not containing quantitative data, or (5) mentioned terms relevant to protected areas and/or to alien/invasive species but only for justification or discussion of results. As a result, 83 abstracts (30\%) qualified for the next round of reviews. These were papers that referred to a type of MPA (fully and/or partially protected areas) and alien/invasive species, or included content that was potentially relevant after reading the abstract alone, and were thus retained for the second step of the analysis.

In the second selection process, the entire 83 articles were read, using the same exclusion criteria listed above, specifically looking for papers that contained data on biological variables (e.g., abundance, biomass, size) of alien species inside and outside MPAs. Besides applying the exclusion criteria used in the first step, we excluded studies that provided evidence on the presence of invasive species only in the MPAs but not in adjacent unprotected (control) sites and vice versa. Finally, 17 studies were suitable for the qualitative and quantitative synthesis (Table S1).

The following information was extracted from each paper (Table S1): (1) year of publication; (2) information on the alien species: name, origin, taxonomic group; (3) information on the MPA: name of the MPA, the year the MPA was established, the geographic location of the case study, the relevant marine biogeographic region ("province" according to Spalding et al., 2007); (5) the year the species was first detected in the region; (6) whether the species is harvested in the study region; (7) the documented impact of the species in the study region (negative, positive, neutral, not assessed), (8) the biological variable measured inside and outside the MPA, (9) the method that was used to measure the variable (e.g., visual census), and (10) the values of the variables inside and outside the MPA (mean values, standard error or deviation, and sample sizes if available). The data were extracted from the text, tables, and figures (using the software WebPlotDigitizer; http://arohatgi. 
info/WebPlotDigitizer/) that were included in the main article and/or Supplementary Material.

\section{Estimation of Effect Size}

We were able to extract sufficient quantitative data (the mean, standard error or deviation, and sample number) for the density (individuals per $\mathrm{m}^{2}$ ) of nine species and the biomass (gr per $\mathrm{m}^{2}$ ) of another three species inside and outside MPAs. All studies followed a control-impact design contrasting evidence from protected and unprotected sites using a variable number of replicates (Table S1). The MPAs were situated in very different geographical locations: British Camp Historical Site, Shaw Island, Argyle Lagoon, Point Caution, Point George, Yellow Island, Low Island, and False Bay MPAs in the San Juan Archipelago, Northwestern Washington State, USA (Byers, 2005; Klinger et al., 2006); Betty's Bay MPA in the Western Cape of South Africa (Malherbe and Samways, 2014); and Hauru, Tiahura, EntreDeux-Baies, Maharepa, Tema'e, Farehau, Maatea, and Haapiti MPAs in Moorea, French Polynesia (Ardura et al., 2015). All species were benthic and included mainly molluscs (ten species: Mytilus galloprovincialis, Crassostera gigas, Drupa albolabris, Littoraria coccinea glabrata, Nerita tessellata, Saccostrea cucullata, Semiricinula tissoti, Nuttallia obscurata, Mya arenaria, Ruditapes philippinarum), as well as one alga (Sargassum muticum) and one bryozoan (Watersipora subtorquata).

We generated a standardized effect size for each species in each MPA. To quantify the effect of protection (e), we used the log-response ratio $\ln \mathrm{R}$ (Hedges et al., 1999), calculated as $\ln \left(\mathrm{X}_{\mathrm{T}} / \mathrm{X}_{\mathrm{C}}\right)$, where $\mathrm{X}_{\mathrm{T}}$ and $\mathrm{X}_{\mathrm{C}}$ are the mean values of density inside (treatment site) and outside the MPA (control site), respectively. We added 0.0001 to all raw abundance values to allow the calculation of $\ln \mathrm{R}$ for species that were absent in the MPA (Molloy et al., 2009). The variance associated with the effect size $\left(v_{e}\right)$ is:

$$
v_{\mathrm{e}}=\frac{\mathrm{S}_{\mathrm{T}}^{2}}{\mathrm{~N}_{\mathrm{T}} \mathrm{X}_{\mathrm{T}}^{2}}+\frac{\mathrm{S}_{\mathrm{C}}^{2}}{\mathrm{~N}_{\mathrm{C}} \mathrm{X}_{\mathrm{C}}^{2}}
$$

where $\mathrm{S}_{\mathrm{T}}$ and $\mathrm{N}_{\mathrm{T}}$ are the standard deviation and sample size of the variable estimated inside the MPA and $S_{C}$ and $N_{C}$ the standard deviation and sample size outside the MPA. A 95\% confidence interval was estimated for each effect size and effect sizes were considered to be significantly different from zero if their confidence interval did not overlap zero.

\section{RESULTS}

The first study providing quantitative data on alien species inside and outside MPAs was published in 1995 (Grosholz and Ruiz, 1995). Yet, the first study that specifically aimed at investigating the performance of alien species in MPAs comparing to unprotected sites was only published 10 years later (Byers, 2005). Eleven out of the 17 studies explicitly refer to this subject providing different conclusions. Some highlight the negative (e.g., Ardura et al., 2015) or positive (e.g., Klinger et al., 2006) effects of MPAs on alien/invasive species, whereas other studies did not find any difference between MPAs and unprotected sites (a summary is provided in Table S2).

The largest proportion of the available literature provides data on alien molluscs $(40 \%, n=10)$, followed by algae $(28 \%, n=7)$ (Figure 1A). Studies have been conducted in only 7 out of 62 marine biogeographic provinces (Figure 1B). The majority of the studies $(70 \%)$ come from the Mediterranean Sea and the Tropical Northwestern Atlantic (more specifically the Caribbean Sea).

Most species were detected in their host environment throughout the 20th century, while the vast majority of MPAs were established between 1980s and 2000s (Table S1). On some occasions, alien species were totally absent from the MPA while present in the broader study area; this was the case for: (1) Mytilus galloprovincialis in the Western Cape of South Africa (Malherbe and Samways, 2014), and (2) Drupa albolabris, Nerita tessellata, Saccostrea cucullata, and Semiricinula tissoti in Moorea, French Polynesia (Ardura et al., 2015). All studies used visual census to estimate the density and/or biomass, or percent cover, or catch rate, or colony size of alien species inside vs. outside MPAs, apart from one that used trapping methods (Thresher et al., 2003). The majority of the alien species $(\sim 70 \%)$ have been reported to have negative impacts on native species and habitats in their host environment while few species (25\%) were harvested in the study region (Table S1).

When we estimated the effect of protection on the density or biomass of individual alien species, we found that protection had a significant negative effect on $50 \%$ of the species (Figure 2). A significant positive effect was detected on 33\% of the species, whereas for the remaining $12 \%$ no statistically significant effect was found. All species showing negative responses to protection were mollusc species in Moorea Island,
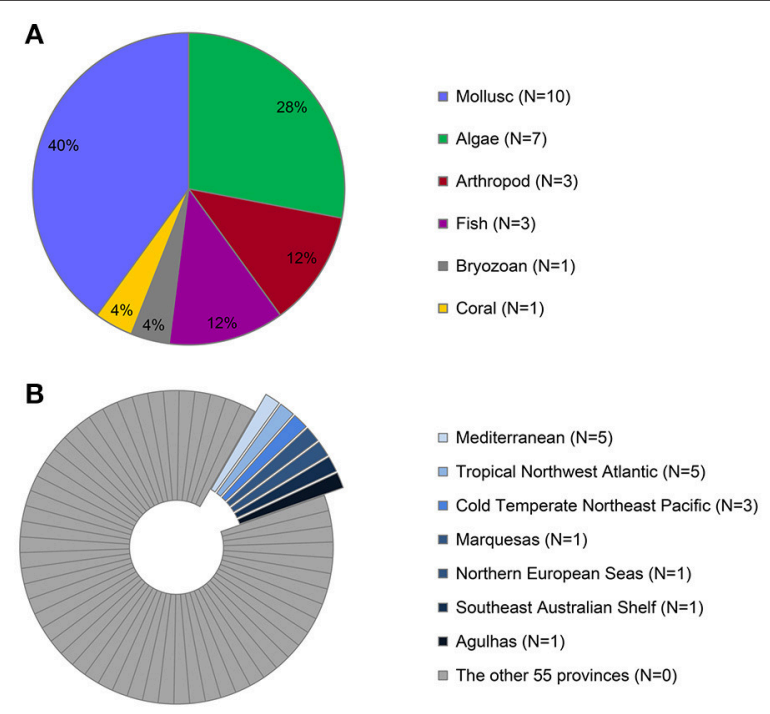

FIGURE 1 | Taxonomic groups studied (A), and geographical distributions (B) of the 17 studies providing data on alien species inside and outside MPAs. (A) Distribution of available information across taxonomic groups; sample sizes are provided in the caption next to each group. (B) Number of studies across 62 marine biogeographic regions ("provinces" according to Spalding et al., 2007). 


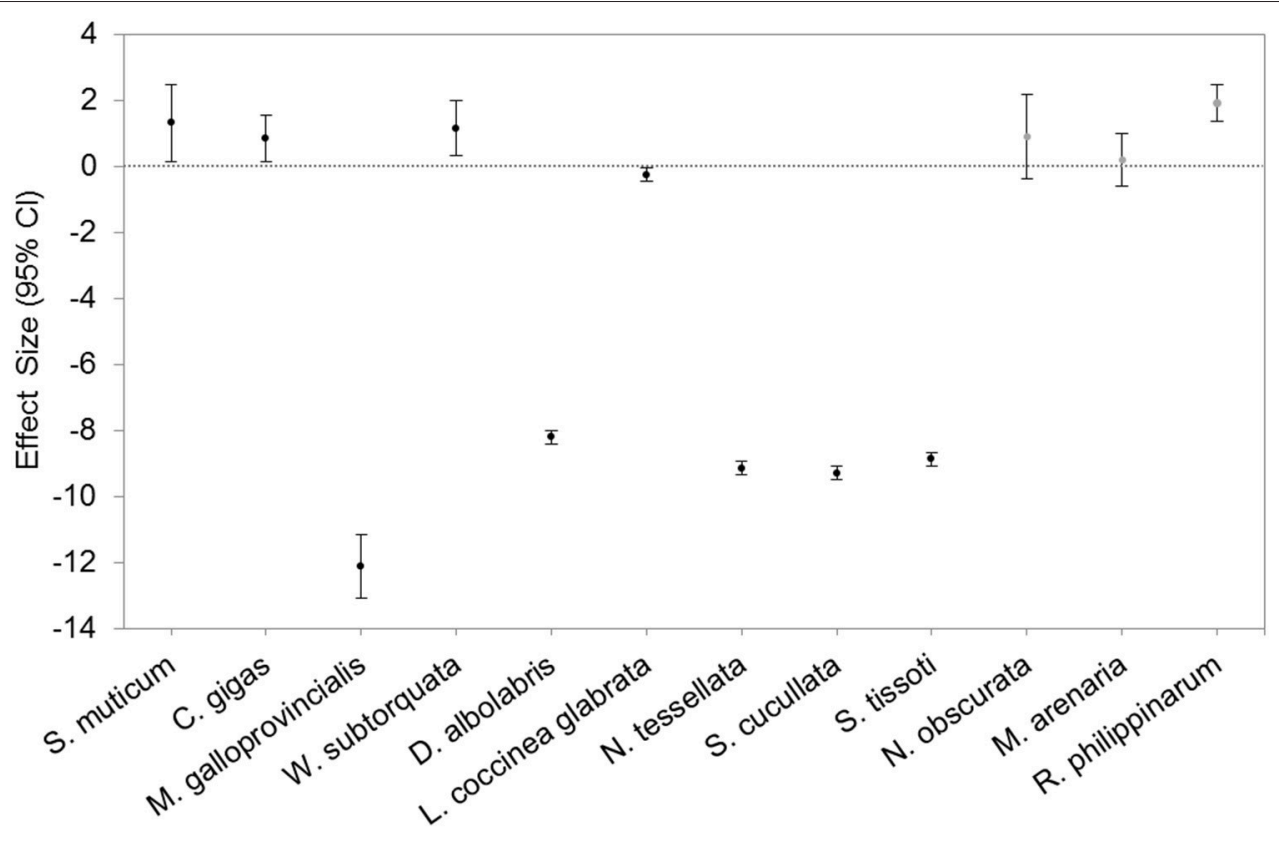

FIGURE 2 | Response ratio (95\% Confidence Interval) of the density of seven and biomass (in gray) of three mollusc species (Mytilus galloprovincialis, Crassostera gigas, Drupa albolabris, Littoraria coccinea glabrata, Nerita tessellata, Saccostrea cucullata, Semiricinula tissoti, Nuttallia obscurata, Mya arenaria, Ruditapes philippinarum), the density of one alga (Sargassum muticum), and the density of one bryozoan (Watersipora subtorquata) in MPAs and outside. The data were extracted from Byers (2005), Klinger et al. (2006), Malherbe and Samways (2014), and Ardura et al. (2015).

French Polynesia (Marquesas) and in Western Cape, South Africa.

\section{DISCUSSION}

Our review demonstrates the scarcity of published evidence on a crucial topic: the effects of MPAs on alien/invasive species. The available data support the hypothesis that alien species respond negatively to protection; the density of most alien species was found to be greater outside than inside MPAs (as shown in Figure 2). Our findings differ from the conclusions of the precedent review article on this topic (Burfeind et al., 2013), according to which alien species do equally well or better within MPAs. This difference in results may be explained by the different methodological approaches and datasets used in each study. However, Burfeind et al. (2013) argue that their conclusions are based on too few data and caution is needed in interpreting their results. We also argue that our results should be considered with caution and that more data on various taxonomic groups across different biogeographic regions are needed to draw robust conclusions. Below, we provide recommendations for advancing knowledge on this important research topic.

Currently, studies based on robust impact assessment designs aiming to investigate the relationships between MPAs and invasive species are scarce (but see Byers, 2005; Klinger et al., 2006). Quantitative studies estimating specific biological and ecological variables (e.g., density, biomass, species richness) should be conducted by sampling alien/invasive species inside MPAs (both in zones of full and partial protection) and outside (control) areas. In most cases, data are not available to compare communities before and after the invasion, so the implementation of BACI (Before-After-Control-Impact) design (Schmitt and Osenberg, 1996) cannot be applied. Yet, replication of control-impact studies using the same sampling protocol and comparing specific variables through time is important, because biological invasions are a dynamic threat (Strayer et al., 2006). Appropriate experimental designs are needed to investigate the mechanisms explaining how MPAs can control the presence and reduce the impacts of alien species within their borders.

Most of the available information ( $\sim 80 \%$ of the species assessed) refers to molluscs and algae. More studies are needed across various taxonomic groups as their responses to protection might differ significantly. In addition, studies within taxonomic groups should examine whether alien species of similar traits have similar responses to protection. Functional traits have been associated with the invasiveness of alien marine species (e.g., Elleouet et al., 2014; Samaha et al., 2016) as well as to the response of native species to protection (e.g., Claudet et al., 2010). Hence, alien/invasive species of similar traits are likely to display similar patterns and tendencies within MPAs. Such information may have important implications for the selection of appropriate management actions as well as for comparing different management options (see Bremner, 2008).

Our results show that information on the effects of protection on alien/invasive species is available for only $11 \%$ of the marine biogeographic regions, even though biological invasions are considered a global threat affecting almost the entire ocean (Bax et al., 2003; Halpern et al., 2008). The response of alien/invasive 
species to protection is likely to be place-specific (Giakoumi et al., 2016). Therefore, the investigation of the effects of MPAs on alien/invasive species in different marine bioregions is a prerequisite for making informed decisions on the uptake of appropriate mitigation measures at a local and regional scale.

The relationships between MPAs and invasive species are likely to be complex. MPA characteristics, such as location, size, level of protection (full vs. partial) and age, as well as dynamic processes within an MPA, such as disturbance regime and magnitude of invasion pressure, can affect the response of alien/invasive species to protection (Burfeind et al., 2013). Unfortunately, the available data do not allow us to disentangle the influence of each factor on the variables under study. Current information is limited and evidence provided is often inconsistent. For example, both studies conducted to assess the performance of the invasive lionfishes (Pterois volitans, $P$. miles) in the Caribbean Sea found that the species presented lower density and biomass in the MPAs than unprotected sites (Mumby et al., 2011; Hackerott et al., 2013). However, one study attributed the lower values within the MPAs to the restoration of predatory relationships (more and larger top predatorsgroupers-controlled the densities of lionfishes within the MPA; Mumby et al., 2011), whereas the other study attributed the lower densities to targeted removal (by spearfishing) within MPAs (Hackerott et al., 2013). Another study examining the effects of MPAs on alien fishes in the Mediterranean Sea, found that the density of alien species did not show any response to protection (Guidetti et al., 2014). Nevertheless, this study lacked appropriate impact assessment design that would allow pairwise comparisons of control and impact sites. Appropriate sampling designs should be applied to investigate not only the effect size of protection on alien/invasive species comparing sites inside and outside MPAs, but also the effects of factors influencing the relationships between MPAs and alien/invasive species.

In conclusion, our review demonstrated the scarcity of evidence on the effects of protection on alien/invasive species.

\section{REFERENCES}

Albins, M. A. (2013). Effects of invasive Pacific red lionfish Pterois volitans versus a native predator on Bahamian coral-reef fish communities. Biol. Inv. 15, 29-43. doi: 10.1007/s10530-012-0266-1

Ardura, A., Juanes, F., Planes, S., and Garcia-Vazquez, E. (2016). Rate of biological invasions is lower in coastal marine protected areas. Sci. Rep. 6:33013. doi: $10.1038 /$ srep 33013

Ardura, A., Planes, S., and Garcia-Vazquez, E. (2015). Aliens in Paradise. Boat density and exotic coastal mollusks in Moorea Island (French Polynesia). Mar. Environ. Res. 112, 56-63. doi: 10.1016/j.marenvres.2015.08.007

Bax, N., Williamson, A., Aguero, M., Gonzalez, E., and Geeves, W. (2003). Marine invasive alien species: a threat to global biodiversity. Mar. Pol. 27, 313-323. doi: 10.1016/S0308-597X(03)00041-1

Boudouresque, C. F., and Verlaque, M. (2005). Nature conservation, marine protected areas, sustainable development and the flow of invasive species to the Mediterranean Sea. Trav. Sci. Parc. Natl. Port-Cros 21, 29-54.

Bremner, J. (2008). Species' traits and ecological functioning in marine conservation and management. J. Exp. Mar. Biol. Ecol. 366, 37-47. doi: $10.1016 /$ j.jembe.2008.07.007
The tropicalization of temperate marine environments (i.e., the increase in the proportion of warm-water species as the ocean warms) can have community-wide effects and threaten iconic ecosystems (Vergés et al., 2016). As biological invasions are a dynamic threat spreading rapidly, especially in humandominated marine environments (Zenetos et al., 2012; Galil et al., 2014), urgent action is required to arrest or mitigate this threat. Assessing whether MPAs-the main management tool currently applied for ocean protection-can control the spread and/or mitigate the impacts of invasive species is critical. Our results indicate that MPAs can have a negative effect on alien/invasive species. Yet, more empirical studies on various species and taxonomic groups in different marine biogeographic regions are necessary to draw robust conclusions.

\section{AUTHOR CONTRIBUTIONS}

SG conceived the idea, conducted the literature review, performed the analyses, and led the writing of the manuscript and all aspects of the project. AP contributed to the literature review, produced the figures, and revised the manuscript.

\section{ACKNOWLEDGMENTS}

This work was conducted within the framework of the ANR project "PAVIS: Assessing the relationships between marine protected areas and invasive species" (Project No. ANR-16ACHN-0016-01). We would like to thank J. E. Byers and M. Vázquez-Luis for their clarifications on the data included in their articles.

\section{SUPPLEMENTARY MATERIAL}

The Supplementary Material for this article can be found online at: http://journal.frontiersin.org/article/10.3389/fmars. 2017.00049/full\#supplementary-material

Burfeind, D. D., Pitt, K. A., Connolly, R. M., and Byers, J. E. (2013). Performance of non-native species within marine reserves. Biol. Inv. 15, 17-28. doi: 10.1007/s10530-012-0265-2

Byers, J. E. (2005). Marine reserves enhance abundance but not competitive impacts of a harvested nonindigenous species. Ecology 86, 487-500. doi: 10.1890/03-0580

Claudet, J., Osendberg, C. W., Domenici, P., Badalamenti, F., Milazzo, M., Falcon, J. M., et al. (2010). Marine reserves: fish life history and ecological traits matter. Ecol. Appl. 20, 830-839. doi: 10.1890/08-2131.1

Edgar, G. J., Stuart-Smith, R. D., Willis, T. J., Kininmonth, S., Baker, S. C., Banks, S., et al. (2014). Global conservation outcomes depend on marine protected areas with five key features. Nature 506, 216-220. doi: 10.1038/nature13022

Elleouet, J., Albouy, C., Ben Rais Lasram, F., Mouillot, D., and Leprieur, F. (2014). A trait-based approach for assessing and mapping niche overlap between native and exotic species: the Mediterranean coastal fish fauna as a case study. Divers. Distrib. 20, 1333-1344. doi: 10.1111/ddi.12235

Fridley, J. D., Stachowicz, J. J., Naeem, S., Sax, D. F., Seabloom, E. W., Smith, M. D., et al. (2007). The invasion paradox: reconciling pattern and process in species invasions. Ecology 88, 3-17. doi: 10.1890/0012-9658(2007)88[3:TIPRPA] 2.0.CO;2 
Galil, B. S., Boero, F., Campbell, M. L., Carlton, J. T., Cook, E., Fraschetti, S., et al. (2014). 'Double trouble': the expansion of the Suez Canal and marine bioinvasions in the Mediterranean Sea. Biol. Inv. 17, 973-976. doi: 10.1007/s10530-014-0778-y

Giakoumi, S. (2014). Distribution patterns of the invasive herbivore Siganus luridus (Rüppell, 1829) and its relation to native benthic communities in the central Aegean Sea, Northeastern Mediterranean. Mar. Ecol. 35, 96-105. doi: 10.1111/maec.12059

Giakoumi, S., Guilhaumon, F., Kark, S., Terlizzi, A., Claudet, J., Felline, S., et al. (2016). Space invaders; biological invasions in marine conservation planning. Divers. Distrib. 22, 1220-1231. doi: 10.1111/ddi.12491

Grosholz, E. D., and Ruiz, G. M. (1995). Spread and potential impact ofthe recently introduced European green crab, Carcinus maenas, in central California. Mar. Biol. 122, 239-247.

Guidetti, P., Baiata, P., Ballesteros, E., Di Franco, A., Hereu, B., Macpherson, E., et al. (2014). Large-scale assessment of mediterranean marine protected areas effects on fish assemblages. PLoS ONE 9:e91841. doi: 10.1371/journal.pone.0091841

Guidetti, P., and Sala, E. (2007). Community-wide effects of marine reserves in the Mediterranean Sea. Mar. Ecol. Prog. Ser. 335, 43-56. doi: 10.3354/meps335043

Hackerott, S., Valdivia, A., Green, S. J., Côté, I. M., Cox, C. E., Akins, L., et al. (2013). Native predators do not influence invasion success of pacific lionfish on caribbean reefs. PLoS ONE 8:e68259. doi: 10.1371/journal.pone.0068259

Halpern, B. S., Walbridge, S., Selkoe, K. A., Kappel, C. V., Micheli, F., D’Agrosa, C., et al. (2008). A global map of human impact on marine ecosystems. Science 319, 948-952. doi: 10.1126/science.1149345

Hedges, L. V., Gurevitch, J., and Curtis, P. S. (1999). The meta-analysis of response ratios in experimental ecology. Ecology 80, 1150. doi: 10.1890/00129658(1999)080[1150:tmaorr]2.0.co;2

Katsanevakis, S., Coll, M., Piroddi, C., Steenbeek, J., Ben Rais Lasram, F., Zenetos, A., et al. (2014a). Invading the Mediterranean Sea: biodiversity patterns shaped by human activities. Front. Mar. Sci. 1:32. doi: 10.3389/fmars.2014.00032

Katsanevakis, S., Wallentinus, I., Zenetos, A., Leppäkoski, E., Çinar, M. E., Oztürk, B., et al. (2014b). Impacts of invasive alien marine species on ecosystem services and biodiversity: a pan-European review. Aquat. Invasions 9, 391-423. doi: 10.3391/ai.2014.9.4.01

Klinger, T., Padilla, D. K., and Britton-Simmons, K. (2006). Two invaders achieve higher densities in reserves. Aquat. Conserv. Mar. Freshw. Eco. 16, 301-311. doi: 10.1002 /aqc.717

Levine, J. M., and D'Antonio, C. M. (1999). Elton revisited: a review of evidence linking diversity and invasibility. Oikos 87, 15-26. doi: 10.2307/3546992

Lubchenco, J., and Grorud-Colvert, K. (2015). Making waves: the science and politics of ocean protection. Science 15, 382-383. doi: 10.1126/science.aad5443

Lubchenco, J., Guidetti, P., Grorud-Colvert, K., Giakoumi, S., Gaines, S., Micheli, F., et al. (2016). The Science of Marine Protected Areas, 3rd Edn., Mediterranean. Partnership for Interdisciplinary Studies of Coastal Oceans and University of Nice Sophia Antipolis. Available online at: www.piscoweb.org

Malherbe, H., and Samways, M. (2014). Rocky shores of a major southern African Marine Protected Area are almost free from intertidal invertebrate alien species. Koedoe 56, 01-05. doi: 10.4102/koedoe.v56il.1206

Molloy, P. P., McLean, I. B., and Côté, I. M. (2009). Effects of marine reserve age on fish populations: a global meta-analysis. J. Appl. Ecol. 46, 743-751. doi: 10.1111/j.1365-2664.2009.01662.x

Molnar, J. L., Gamboa, R. L., Revenga, C., and Spalding, M. D. (2008). Assessing the global threat of invasive species to marine biodiversity. Front. Ecol. Environ. 6, 485-492. doi: 10.1890/070064
Mumby, P. J., Harborne, A. R., and Brumbaugh, D. R. (2011). Grouper as a natural biocontrol of invasive lionfish. PLOS ONE 6:e21510. doi: 10.1371 /journal.pone.0021510

Pyšek, P., and Richardson, D. (2010). Invasive species, environmental change and management, and health. Annu. Rev. Environ. Resour. 35, 25-55. doi: 10.1146/annurev-environ-033009-095548

Samaha, C., Dohna, H., and Bariche, M. (2016). Analysis of RedSea fish species' introductions into the Mediterraneanreveals shifts in introduction patterns. $J$. Biogeogr. 43, 1797-1807. doi: 10.1111/jbi.12793

Schmitt, R. J., and Osenberg, C. W. (1996). Detecting Ecological Impacts: Concepts and Applications in Coastal Habitats. London: Academic Press.

Selig, E. R., and Bruno, J. F. (2010). A global analysis of the effectiveness of marine protected areas in preventing coral loss. PLoS ONE 5:e9278. doi: 10.1371/journal.pone.0009278

Simberloff, D., Martin, J. L., Genovesi, P., Maris, V., Wardle, D. A., Aronson, J., et al. (2013). Impacts of biological invasions: what's what and the way forward. Trends Ecol. Evol. 28, 58-66. doi: 10.1016/j.tree.2012.07.013

Spalding, M. D., Fox, H. E., Allen, G. R., Davidson, N., Ferdaña, Z. A., Finlayson, M., et al. (2007). Marine ecoregions of the world: a bioregionalization of coastal and shelf areas. Bioscience 57, 573-583. doi: 10.1641/B570707

Stohlgren, T. J., Barnett, D., Flather, C., Fuller, P., Peterjohn, B., Kartesz, J., et al. (2006). Species richness and patterns of invasion in plants, birds, and fishes in the United States. Biol. Inv. 8, 427-447. doi: 10.1007/s10530-005-6422-0

Strayer, D. L., Eviner, V. T., Jeschke, J. M., and Pace, M. L. (2006). Understanding the long-term effects of species invasions. Trends Ecol. Evol. 21, 645-651. doi: 10.1016/j.tree.2006.07.007

Thresher, R. E., and Kuris, A. M. (2004). Options for managing invasive marine species. Biol. Inv. 6, 295-300. doi: 10.1023/B:BINV.0000034598.2 8718.2e

Thresher, R., Proctor, C., Ruiz, G., Gurney, R., MacKinnon, C., Walton, W., et al. (2003). Invasion dynamicsof the European shore crab, Carcinus maenas, in Australia. Mar. Biol. 142, 867-876. doi: 10.1007/s00227-003-1011-1

Vergés, A., Doropoulos, C., Malcolm, H. A., Skye, M., Garcia-Pizá, M., Marzinelli, E. M., et al. (2016). Long-term empirical evidence of ocean warming leading to tropicalization of fish communities, increased herbivory, and loss of kelp. Proc. Nat. Acad. Sci. U.S.A. 113, 13791-13796. doi: 10.1073/pnas.1610725113

Vergés, A., Steinberg, P. D., Hay, M. E., Poore, A. G., Campbell, A. H., Ballesteros, E., et al. (2014). The tropicalization of temperate marine ecosystems: climatemediated changes in herbivory and community phase shifts. Proc. Biol. Sci. 281:20140846. doi: 10.1098/rspb.2014.0846

Zenetos, A., Gofas, S., Morri, C., Rosso, A.,Violanti, D., García Raso, J. E., et al. (2012). Alien species in the Mediterranean Sea by 2012. A contribution to the application of European Union's Marine Strategy Framework Directive (MSFD). Part 2. Introduction, trends and pathways. Mediterr. Mar. Sci. 13, 328-352. doi: $10.12681 / \mathrm{mms} .327$

Conflict of Interest Statement: The authors declare that the research was conducted in the absence of any commercial or financial relationships that could be construed as a potential conflict of interest.

Copyright (c) 2017 Giakoumi and Pey. This is an open-access article distributed under the terms of the Creative Commons Attribution License (CC BY). The use, distribution or reproduction in other forums is permitted, provided the original author(s) or licensor are credited and that the original publication in this journal is cited, in accordance with accepted academic practice. No use, distribution or reproduction is permitted which does not comply with these terms. 